\title{
Consensus on the pathological definition and classification of poorly cohesive gastric carcinoma
}

\author{
C. Mariette ${ }^{1}$. F. Carneiro ${ }^{2} \cdot$ H. I. Grabsch ${ }^{3,4} \cdot$ R. S. van der Post ${ }^{5} \cdot$ W. Allum ${ }^{6} \cdot$ Giovanni de Manzoni $^{7}$ on behalf of \\ European Chapter of International Gastric Cancer Association
}

Received: 18 March 2018 / Accepted: 16 August 2018 / Published online: 25 August 2018

(c) The International Gastric Cancer Association and The Japanese Gastric Cancer Association 2018

\begin{abstract}
Background and aims Clinicopathological characteristics of gastric cancer (GC) are changing, especially in the West with a decreasing incidence of distal, intestinal-type tumours and the corresponding increasing proportion of tumours with Laurén diffuse or WHO poorly cohesive (PC) including signet ring cell (SRC) histology. To accurately assess the behaviour and the prognosis of these GC subtypes, the standardization of pathological definitions is needed.

Methods A multidisciplinary expert team belonging to the European Chapter of International Gastric Cancer Association (IGCA) identified 11 topics on pathological classifications used for PC and SRC GC. The topics were debated during a dedicated Workshop held in Verona in March 2017. Then, through a Delphi method, consensus statements for each topic were elaborated.

Results A consensus was reached on the need to classify gastric carcinoma according to the most recent edition of the WHO classification which is currently WHO 2010. Moreover, to standardize the definition of SRC carcinomas, the proposal that only WHO PC carcinomas with more than $90 \%$ poorly cohesive cells having signet ring cell morphology have to be classified as SRC carcinomas was made. All other PC non-SRC types have to be further subdivided into PC carcinomas with SRC component $(<90 \%$ but $>10 \%$ SRCs) and PC carcinomas not otherwise specified $(<10 \%$ SRCs).

Conclusion The reported statements clarify some debated topics on pathological classifications used for PC and SRC GC. As such, this consensus classification would allow the generation of evidence on biological and prognostic differences between these GC subtypes.
\end{abstract}

Keywords Gastric cancer $\cdot$ Poorly cohesive sub-type $\cdot$ Signet ring cell histology

\section{Introduction}

Despite a declining incidence, gastric cancer (GC) is still one of the major causes of cancer death worldwide [1]. Evidence has accumulated over the last decades that

Giovanni de Manzoni

giovanni.demanzoni@univr.it

Department of Surgery, Hôpital Claude-Huriez, Lille, France

2 Departments of Pathology, Centro Hospitalar São João, Faculty of Medicine of Porto University and Institute for Research and Innovation in Health (i3S), Institute of Molecular Pathology and Immunology of the University of Porto (Ipatimup), Porto, Portugal

3 Department of Pathology, GROW School for Oncology and Developmental Biology, Maastricht University Medical Center, Maastricht, The Netherlands clinicopathological characteristics of GC are changing, especially in the West [2-4] with a decreasing incidence of distal, intestinal type tumours and the corresponding increasing proportion of tumours with Laurén diffuse [5] or WHO [6]

4 Pathology and Tumour Biology, Leeds Institute of Cancer and Pathology, University of Leeds, Leeds, UK

5 Department of Pathology, Radboud university medical center, Nijmegen, The Netherlands

6 Department of Upper Gastrointestinal Surgery, Royal Marsden Hospital, London, UK

7 General and Upper GI Surgery Division, Department of Surgery, University of Verona, Piazzale Stefani 1, 37126 Verona, Italy 
poorly cohesive (PC) including signet ring cell (SRC) histology [2-4].

Conflicting data exist about the prognostic relevance of SRC histology [7, 8]. While some authors report a relationship between SRC histology and poor prognosis [7], other studies have not confirmed this finding [8]. More recently, some comparative studies from Western and Asian authors $[9,10]$ suggested that the prognostic impact of SRC histology depends on the stage of the disease, being favourable in early stages but adverse in advanced tumour stages. One of the main reasons for these inconsistent findings over the relationship between SRC and prognosis appears to be a lack of standardization of GC histological subtype definitions. The 2010 WHO classification [6] defines PC tumours as GC composed of isolated or small groups of tumour cells. If neoplastic cells with SRC morphology predominate in the tumour, the tumour is defined as SRC carcinoma. In reality, the terms Laurén "diffuse type", "poorly cohesive" and "signet ring cell" GC are often used indiscriminately. As a consequence, tumours having major and minor SRC components may have been inappropriately considered together in comparative studies [11].

Standardization of terminology and classifications is a crucial step to accurately assess epidemiological trends and to allow prediction of prognosis and/or response to chemotherapy of GC patients with SRC as well as PC non-SRC tumours compared to other GC subtypes and to design tailored treatment strategies. To reach a consensus on the pathological classification of PC and SRC GC, a multidisciplinary expert team belonging to the European Chapter of International Gastric Cancer Association (IGCA) attended a dedicated Workshop in Verona in March 2017.

\section{Methods}

The methodology of this project was similar to that of other multicentric consensus reports $[12,13]$. After establishing the purpose of the project, a restricted working group (RWG) of the European Chapter of IGCA identified areas of uncertainty about the histopathological definitions and classifications of PC and SRC gastric cancers to define the topics for debate.

Next, an expanded working group (EWG) of European experts (Table 1) was invited to take part in a dedicated workshop held in Verona, Italy, on the 17th of March, 2017. During the workshop, the previously identified topics were discussed and a draft statement in response to each topic was recorded.

Each expert was asked to comment and suggest modifications to the draft statements through a Delphi method implementation. These suggestions were made available to the other experts in a series of web-based discussion rounds
Table 1 List of participants at the Verona Workshop on poorly cohesive and signet ring cell gastric cancer

\begin{tabular}{|c|c|c|c|}
\hline Name & & Country & Speciality \\
\hline Allum & William & United Kingdom & Surgeon \\
\hline Baiocchi & Gian Luca & Italy & Surgeon \\
\hline Carneiro & Fatima & Portugal & Pathologist \\
\hline De Manzoni & Giovanni & Italy & Surgeon \\
\hline Flejou & Jean-Francois & France & Pathologist \\
\hline Fumagalli & Uberto & Italy & Surgeon \\
\hline Grabsch & Heike & Netherlands & Pathologist \\
\hline Hoelscher & Arnulf & Germany & Surgeon \\
\hline Iglesias & Mar & Spain & Pathologist \\
\hline Mariette & Christophe & France & Surgeon \\
\hline Marrelli & Daniele & Italy & Surgeon \\
\hline Moenig & Stefan & Switzerland & Surgeon \\
\hline Morgagni & Paolo & Italy & Surgeon \\
\hline Pera & Manuel & Spain & Surgeon \\
\hline Piessen & Guillaume & France & Surgeon \\
\hline Reim & Daniel & Germany & Surgeon \\
\hline Renaud & Florence & France & Pathologist \\
\hline Roviello & Franco & Italy & Surgeon \\
\hline Saragoni & Luca & Italy & Pathologist \\
\hline Scarpa & Aldo & Italy & Pathologist \\
\hline Schneider & Paul & Switzerland & Surgeon \\
\hline Tomezzoli & Anna & Italy & Pathologist \\
\hline Vanderpost & Chella & Netherlands & Pathologist \\
\hline Vieth & Michael & Germany & Pathologist \\
\hline Wotherspoon & Andrew & United Kingdom & Pathologist \\
\hline Zamboni & Giuseppe & Italy & Pathologist \\
\hline
\end{tabular}

for further discussion and definitive approval. The grade of expert agreement to each statement is reported.

\section{Results}

Consensus statements are reported as follows. There was unanimous agreement to each statement, except for the statement 5 where one of the experts disagreed.

\section{Topic 1}

\section{What is the unequivocal definition of a signet ring cell (SRC)?}

\section{Statement 1}

The definition of a signet ring cell is that of a cell with ample cytoplasmic mucin which appears optically clear on haematoxylin and eosin (HE) staining and an eccentrically placed nucleus [6]. All other poorly cohesive cancer cells that do 
not display this specific morphology should be classified as poorly cohesive cells (PC) not otherwise specified (NOS).

\section{Topic 2}

Is a cell with signet ring morphology always a malignant cell? What are the main differential diagnoses of cells with poorly cohesive/signet ring cell morphology?

\section{Statement 2}

No, a cell with signet ring morphology is not always malignant. There are benign lookalikes that can mimic signet ring cell carcinoma which are illustrated in Figs. 1 and 2 [14]. Furthermore, dystrophic goblet cells, non-neoplastic epithelial cells associated with ulceration and ischaemia, macrophages or mesothelial cells in cytology preparations can look like signet ring cells.

Apart from benign signet ring cell change, lymphoma, poorly differentiated intestinal gastric adenocarcinoma, neuroendocrine tumours, metastatic lobular breast cancer, ovarian cancer and melanoma should be considered in the differential diagnosis of signet ring cell carcinoma.

\section{Topic 3}

Can SRC carcinoma be identified by other means than HE morphology? Are there routinely used immunohistochemical (IHC) marker and if so, what are they?

\section{Statement 3}

Currently, there are no specific IHC markers used routinely. E-cadherin or cytokeratin subtyping do not aid in the identification of signet ring cells. However, histochemical staining for mucin (AB-PAS) can be used to confirm the presence of mucin in signet ring cells.

\section{Topic 4}

Currently, the terms "diffuse type" cancers according to Laurén classification, "poorly cohesive carcinomas" according to the WHO classification 2010, "signet ring cell" carcinomas, and "linitis plastica" are used indiscriminately. How can terminology used to describe the histology of these tumours be standardized?

\section{Statement 4}

In the pathology report, gastric adenocarcinoma should be classified according to the most recent edition of the WHO classification which is currently the 4th edn published in
2010 [6]. The Laurén "diffuse" type [5] corresponds to the WHO category of "poorly cohesive" carcinomas.

The WHO 2010 category of PC carcinoma includes SRC which is defined as PC carcinoma that contains predominantly or exclusively signet ring cells (See Statement 5).

The term "linitis plastica" should only be used for the description of the macroscopic characteristics of the tumour.

\section{Topic 5}

A SRC carcinoma is defined according to the WHO as PC carcinoma containing predominantly or exclusively signet ring cells. Should an internationally standardized method be used, to define the proportion of signet ring cells required to subclassify tumours with signet ring cells?

\section{Statement 5}

To standardize the definition of SRC cancers, we propose that only WHO PC carcinomas with more than $90 \%$ poorly cohesive cells having classical signet ring cell morphology should be classified as SRC carcinomas.

We propose to use the following subclassification of PC and SRC carcinomas (Fig. 3):

- Signet ring cell (SRC) type ( $>90 \%$ of signet ring cells)

- Combined poorly cohesive NOS and SRC carcinoma (PC-NOS/SRC; $<90 \%$ but $>10 \%$ of signet ring cells)

- Poorly cohesive NOS (PC-NOS; $<10 \%$ of signet ring cells)

We believe that using the above categories of poorly cohesive carcinomas, and comparing tumours with almost exclusive ( $>90 \%)$ signet ring cells to those with lower ( $<90 \%$ but $>10 \%$ and $<10 \%$ ) proportion of signet ring cells in retrospective and prospective studies, the prognostic differences of PC tumours with different proportion of cells with signet ring morphology can be accurately investigated.

It is important that these categories/subclassifications are only used for PC and SRC carcinomas. Mucinous cancers are characterized by the presence of extracellular mucin in more than $50 \%$ of the tumour area. Even if mucinous cancers contain signet ring cells, they should not be classified as poorly cohesive/signet ring cell carcinomas as mucinous cancers have different biology and prognosis.

\section{TOPIC 6}

How big is the discrepancy between histological tumour type in endoscopic biopsies and resected specimen in gastric cancer using the current WHO classification? Do 
Fig. 1 Mimickers of signet ring cell carcinoma in gastric mucosa. a Vacuolization of the foveolar epithelium; $\mathbf{b}$ hyperplastic polyp with globoid change; c glassy cell change; $\mathbf{d}$ prominent mucous neck cells; $\mathbf{e}$ ischemic/autolytic change with loss of epithelial cells and signet cell change in a hyperplastic polyp; f neuroendocrine tumour; g low grade dysplasia and dystrophic intestinal metaplasia; h xanthoma (H\&E, original magnifications $\times 200-400$ )
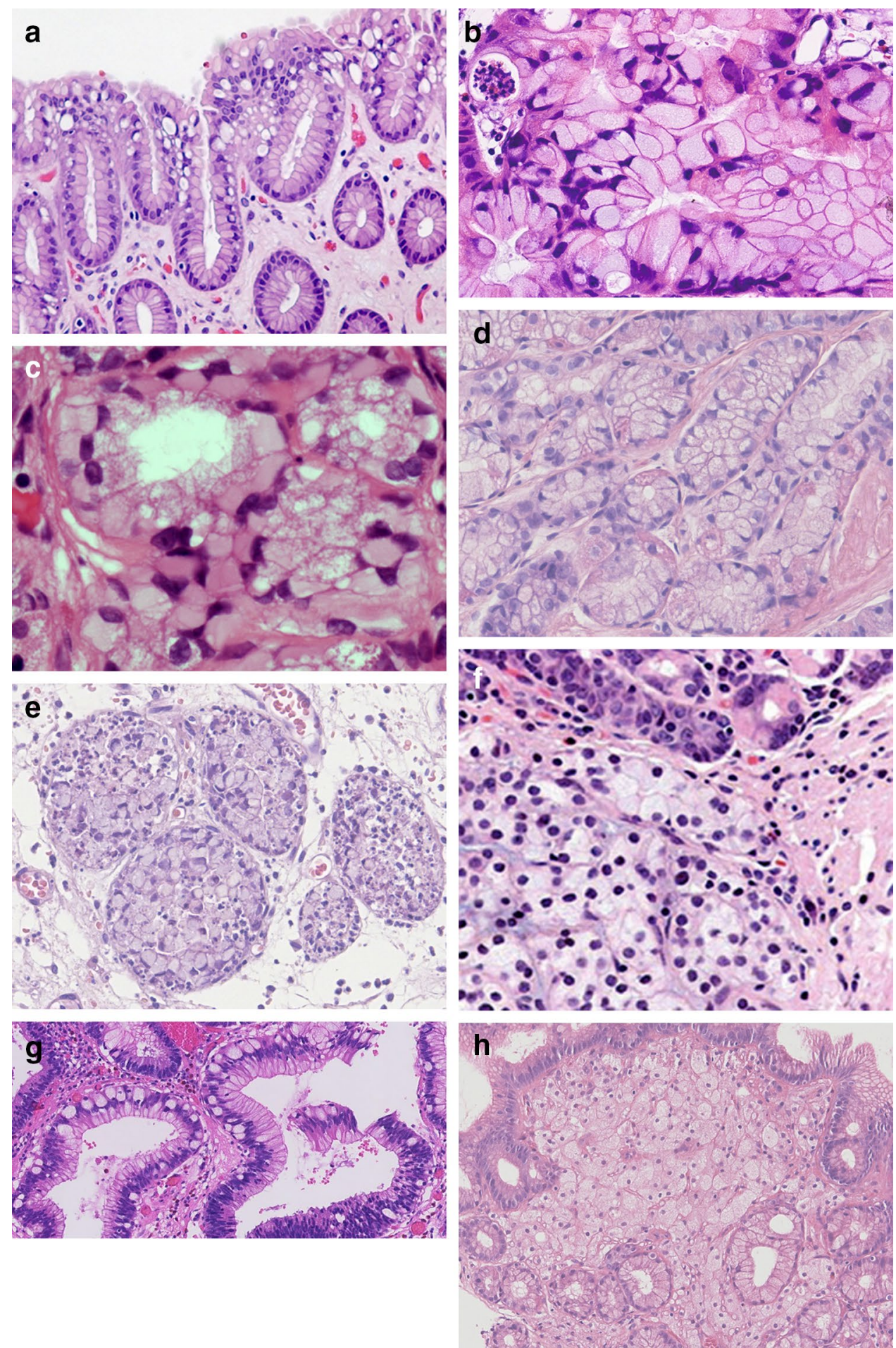

you believe that this discrepancy is larger for PC/SRC carcinomas?

\section{Statement 6}

Due to the uncertainty about the definition used when reporting results, it is currently unclear whether there is a discrepancy between biopsy classification and resection specimen classification. We therefore believe that it is necessary to report in PC carcinoma whether signet ring cells are present in specimens. The concordance between preoperative biopsies and resected specimens according to the proposed definitions (statement 5) should be assessed. 


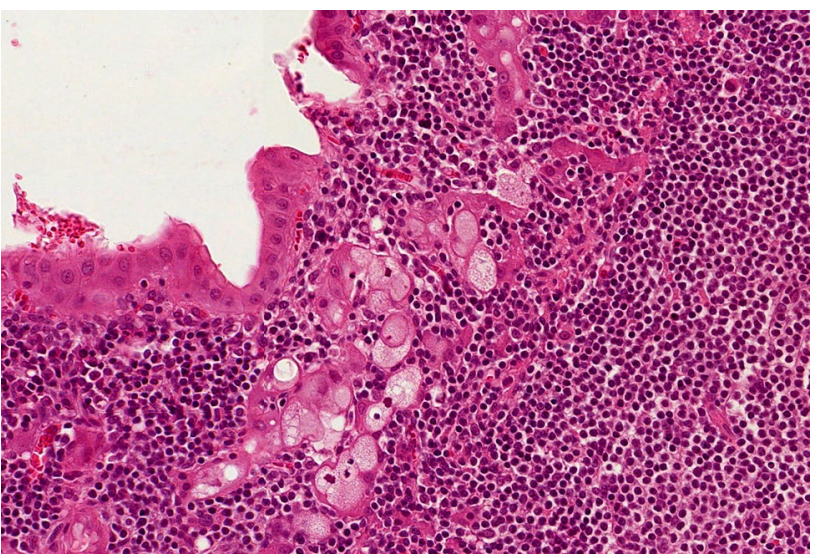

Fig. 2 Carcinoma-like signet ring cells in MALT lymphoma: multiple-single clusters of SRCs characterized by abundant pale cytoplasm and a small peripheral nucleus, intermingled with diffuse infiltrate of marginal-zone B cells

\section{Topic 7}

Is the determination of the pathological depth of invasion (pT category) in PC/SRC carcinomas, in particular regarding the involvement of the serosa, more difficult than in other histological types of gastric cancer?

\section{Statement 7}

There are more difficulties in determining the pathological $\mathrm{T}$ category in PC and SRC carcinomas. Immunohistochemical staining for cytokeratin does not help as the mesothelial cells of the serosa also express cytokeratins. Elastica stains may be helpful to identify the location of the serosa.

\section{Topic 8}

Is the type of stroma reaction the same in all SRC cancers? If not, do you think this could have a prognostic impact?

\section{Statement 8}

The stroma reaction is not the same in all PC and SRC carcinomas. The stroma reaction may change depending on depth of tumour invasion. It is likely that the type of stroma reaction has a prognostic impact, but available data are limited [15].

\section{Topic 9}

Does neoadjuvant treatment modify gastric cancer histopathological phenotype? Can a histopathological response to neoadjuvant chemotherapy (tumour regression grade) be established in SRC carcinomas in the same
Fig. 3 Poorly cohesive gastric carcinoma, examples of morphology. a Signet ring cell carcinoma (SRCC) $(>90 \%$ of signet ring cells): classical signet ring cells are seen at the superficial layer of gastric mucosa; $\mathbf{b}$ combined PCC-NOS and SRCC (PCC-NOS/ SRC) $(<90 \%$ but $>10 \%$ of signet ring cells): this case has two components, the superficial part is composed of classical signet ring cells and the deeper part is composed by poorly cohesive, non-signet ring cells; c combined PCC-NOS and SRCC (PCC-NOS/ SRC) $(<90 \%$ but $>10 \%$ of signet ring cells): in this case, the two cell types (signet ring and poorly cohesive cells) are intermingled; $\mathbf{d}$ poorly cohesive carcinoma NOS (PCCNOS) $(<10 \%$ of signet ring cells): the poorly cohesive, nonsignet ring cells, are invading the muscle layer $(\mathrm{H} \& \mathrm{E}$, original magnifications $\times 200-400$ )
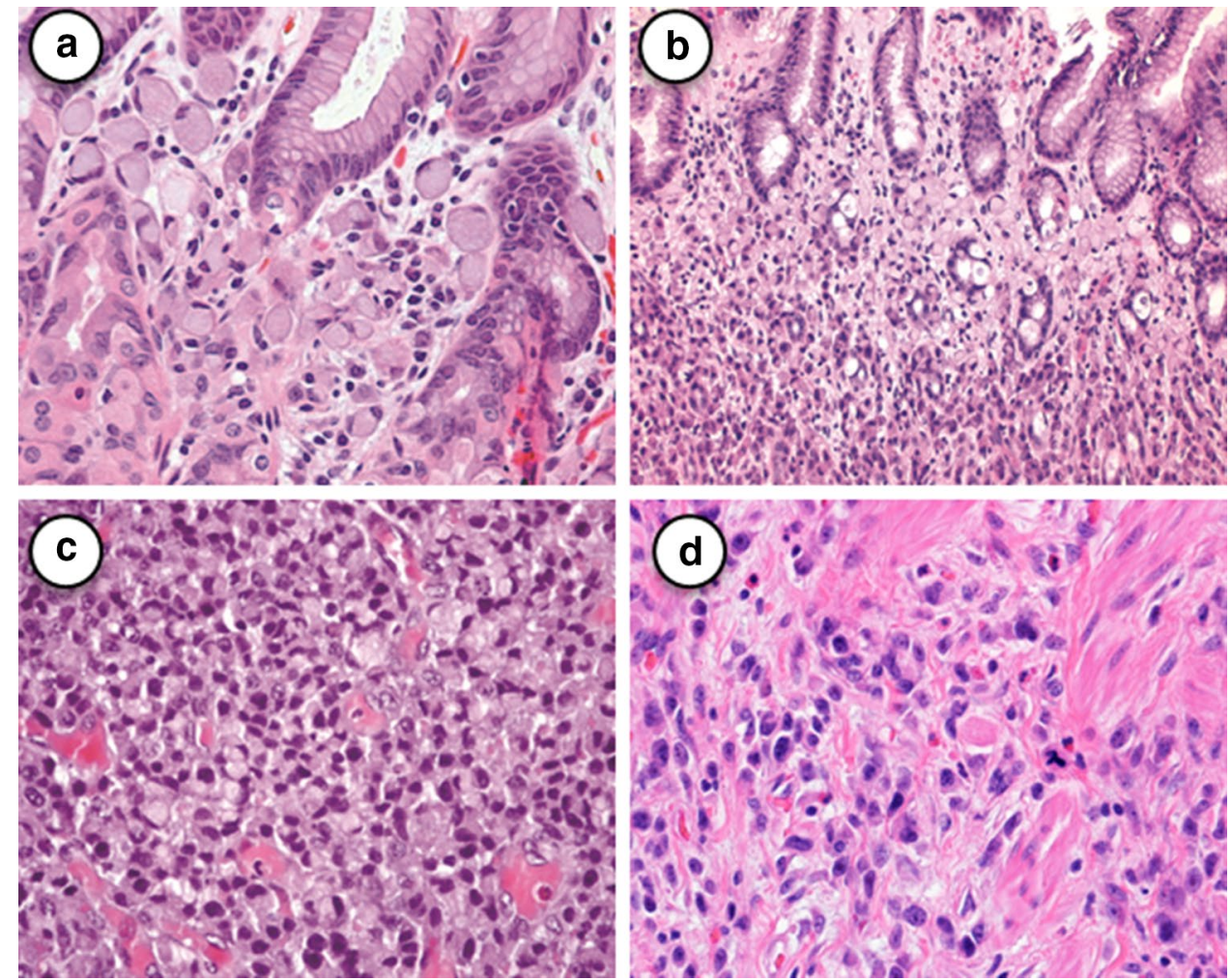
way as in non-SRC carcinomas? Are there specific pathological criteria to assess the response to neoadjuvant treatments in SRC carcinoma?

\section{Statement 9}

Apart from seeing regressive features such as fibrosis and necrosis, there is no definitive evidence that the histological phenotype of cancer cells change after neoadjuvant chemotherapy.

In GC patients who received neoadjuvant therapy, we only have the pretreatment diagnostic biopsy to determine the tumour phenotype. There is no evidence yet that the tumour phenotype changes after chemo(radio)therapy. By reviewing slides of resected specimens from clinical trials comparing surgery alone to neoadjuvant therapy followed by surgery, we could evaluate the impact of neoadjuvant therapy on the histological tumour phenotype in gastric adenocarcinoma including in tumours with PC/SRC histology classified on the pretreatment diagnostic biopsies.

At the moment, there are no specific pathologic criteria to assess the response to neoadjuvant treatment in poorly cohesive and signet ring cell types.

Tumour regression grade according to Becker [16] or Mandard [17] is currently reported in pathological reports in most Western countries. It is noteworthy that pathologists have difficulties in particular in PC GC in differentiating treatment naïve desmoplastic stroma from treatment-induced fibrosis. It therefore appears necessary to develop specific pathologic regression systems for PC and SRC tumours.

Of note, these pathologic regression systems should include not only regression grading for the primary tumour but also for the lymph nodes. Indeed, for oesophageal and cardia cancer [18-24] the prognostic relevance of nodal response to preoperative treatments has already been demonstrated, and this is likely to be significant in gastric cancer, too.

It would be very interesting to evaluate the rates of pathologic tumour and nodal response to preoperative treatment according to the proportion of signet ring cells, i.e. based on the classification proposed in Statement 5.

\section{Topic 10}

Is it possible to find signet ring cells also in the context of tubular or papillary gastric adenocarcinoma? If yes, how do you classify this tumour?

\section{Statement 10}

The WHO classification 4th edn [6] defines 'mixed adenocarcinoma' as a tumour with a discrete component of tubulopapillar and a poorly cohesive-SRC component. It means that each component should be clearly separate. There is currently no cut-off defined with respect to percentage of each component for a tumour to be classified as mixed adenocarcinoma. However, if only rare signet ring cells/rare poorly cohesive cells are present, for example at the invasive edge, the tumour should still be classified as tubular or papillary tumour.

\section{Topic 11}

In case of WHO mixed type gastric cancers, is there pathological evidence that the PC/SRC component is more 'aggressive' showing a higher frequency of lymph node metastases?

\section{Statement 11}

Both, the tubulo-papillary and PC-SRC components may be aggressive.

The two components have different pathways of tumour dissemination with the tubulo-papillary (Laurén: intestinal type) component spreading more frequently by angioinvasion, while the PC-SRC (Laurén: diffuse type) component tend to metastasise to the peritoneum [25].

Currently, one can only speculate that the cumulative effect of the adverse behaviours of intestinal and diffuse-type gastric carcinoma is responsible for the greater biological aggressiveness of mixed-type gastric carcinoma compared to "pure" intestinal and diffuse gastric carcinoma [26-33]. The level of existing evidence is too low for a definitive conclusion.

\section{Discussion}

The proportion of Laurén diffuse and WHO PC and SRC gastric cancer subtypes have increased in recent years, especially in the West [2-4]. Some studies reported an independent unfavourable prognostic impact of SRC histology compared to other histotypes [7], while others could not confirm this [8]. More recently, a stage-dependent prognostic role of SRC has been suggested by Western and Eastern authors $[9,10]$. Different proportions of early and advanced SRC tumours in the published series may have caused the inconsistency of data reported so far.

Most importantly, there is no standardization in the terminology used to define tumours with signet ring cells and very often the definitions of "diffuse type" cancers according to Laurén classification, "poorly cohesive" and "signet ring cell" gastric carcinomas according to the 2010 WHO classification, or "linitis plastica" are used indiscriminately. Findings reported in comparative studies [7-10] could have been affected by the heterogeneity of SRC and non-SRC cancers. 
Table 2 Comparison of different classifications of gastric cancer (Laurén, Nakamura, WHO and Japanese classifications)

\begin{tabular}{|c|c|c|c|c|c|}
\hline \multirow{2}{*}{$\begin{array}{l}\text { Laurén (1965) } \\
\text { Intestinal }\end{array}$} & \multirow{2}{*}{$\frac{\text { Nakamura (1968) }}{\text { Differentiated }}$} & \multicolumn{2}{|l|}{ WHO (2010) } & \multicolumn{2}{|c|}{ Japanese classification (2017) } \\
\hline & & Common type: & $\begin{array}{l}\text { Papillary } \\
\text { Tubular }\end{array}$ & Common type & $\begin{array}{l}\text { Papillary: pap } \\
\text { Tubular } 1 \text { (well-differentiated): tub1 } \\
\text { Tubular } 2 \text { (moderately differentiated): } \\
\text { tub2 }\end{array}$ \\
\hline Intestinal/diffuse & $\begin{array}{l}\text { Differentiated/ } \\
\text { undifferentiated }\end{array}$ & Common type: & Mucinous & Common type & Mucinous \\
\hline Diffuse & Undifferentiated & Common type: & $\begin{array}{l}\text { Poorly cohesive, SRC phenotype } \\
\text { Poorly cohesive, other cell types }\end{array}$ & Common type & $\begin{array}{l}\text { SRC carcinoma: sig } \\
\text { Poorly } 2 \text { (non-solid type): por2 }\end{array}$ \\
\hline Mixed & Undifferentiated & Common type: & Mixed & & $\begin{array}{l}\text { Description according to the propor- } \\
\text { tion } \\
(\text { e.g. por } 2>\operatorname{sig}>\text { tub2) }\end{array}$ \\
\hline \multirow[t]{2}{*}{ Indeterminate } & Undifferentiated & Common type: & $\begin{array}{l}\text { Poorly differentiated tubular } \\
\text { (solid) carcinoma }\end{array}$ & Common type: & Poorly 1 (solid type): por1 \\
\hline & & Special type: & Undifferentiated carcinoma & Special type: & Undifferentiated carcinoma \\
\hline
\end{tabular}

To establish reproducible definitions towards standardized classification of gastric cancer, a European consensus group has produced the definitions described in this paper.

The two key issues for pathologists are first, that gastric carcinoma should be classified according to the most recent edition of the WHO classification which is currently WHO 2010 [6]. The Laurén "diffuse" type corresponds to the WHO category of "poorly cohesive" carcinomas.

Second, to standardize the definition of SRC carcinomas, we propose that only WHO PC carcinomas with more than $90 \%$ poorly cohesive cells having signet ring cell morphology should be classified as SRC carcinomas. All other PC non-SRC types should be further subdivided into PC carcinomas with SRC component $(<90 \%$ but $>10 \%$ signet ring cells) and PC carcinomas NOS $(<10 \%$ signet ring cells). This classification reflects the hypothesis that the extent of SRCs may represent a differentiation grade in PC and SRC carcinomas. Studies in Hereditary Diffuse Gastric Cancer (HDGC) suggest that intramucosal lesions morphologically characterized by typical signet ring cells without expression of Ki67 and p53 represent an "indolent" phenotype. By contrast advanced carcinomas that display an "aggressive" phenotype with positive immunoreaction for Ki67 and p53, are composed of poorly cohesive pleomorphic cells without SRC morphology [34]. A recent study in Korean patients with gastric PC carcinoma subclassified each tumour on the basis of the prevalent histopathological component into "pure" SRC type (signet ring cells $>95 \%$ ), "pure" PC not otherwise specified (PCC-NOS) type (i.e. no SRC), mixed SRC-predominant type (SRC $>$ PCC-NOS, $\mathrm{SRC}>50 \%$ ) or mixed PCC-NOS-predominant type (PCC-NOS $>$ SRC) [35]. A distinct mutation pattern and significant differences in overall survival were reported for "pure" SRC type and "pure" PC not otherwise specified type, with better outcome for the former category. These findings support our proposal to distinguish different subcategories of PC gastric carcinoma. Such classification would allow the generation of evidence on biological and prognostic differences of these tumours according to the proportion of signet ring cells.

In the Japanese pathological classification [36], the poorly differentiated non-solid type (por2) category that substantially corresponds to the WHO category of PC non-SRC type, is considered separately from the SRC type (Table 2). In addition, in recent papers, Japanese authors [37] confirm that histopathological features of signet ring cell types differ from those of poorly differentiated (por2) tumours and highlight the need to differentiate them in clinical studies.

It is important that pathologists attempt to subclassify gastric cancer on biopsies (when adequate biopsies are available) and not use the term 'adenocarcinoma NOS', since most patients will receive preoperative treatment which may change tumour morphology. Future clinical and translational research should include the creation of specific pathologic regression systems for tumours with PC/SRC, but also a more in-depth analysis of role of stroma reaction and genomic characteristics of these subtypes of gastric cancer.

Acknowledgements Baiocchi Gian Luca (University of Brescia, Brescia, Italy); Bencivenga Maria (University of Verona, Verona, Italy), Flejou Jean-Francois (Hôpitaux Universitaires Est Parisien, Hôpital Saint-Antoine, Paris, France); Fumaglli Uberto (Spedali Civili, Brescia, Italy); Hoelscher Arnulf (Agaplesion Markus Krankenhaus, Frankfurt, Germany); Iglesias Mar (Hospital Universitario del Mar, Barcelona, Spain); Marrelli Daniele (University of Siena, Siena, Italy); Moenig Stephan (Hôpitaux Universitaires de Genève, Genève, Switzerland); Morgagni Paolo (G.B. Morgagni-L Pierantoni Hospital, Forlì, Italy); Pera Manuel (Hospital Universitario del Mar, Barcelona, Spain); Piessen Giullaume (University Hospital of Lille, Lille, France); Reim Daniel (Klinikum Rechts der Isar der Technischen Universität München, Munich, Germany); Renaud Florence (University Hospital of Lille, Lille, France); Roviello Franco (University of Siena, Siena, Italy); Saragoni Luca (G.B. Morgagni-L. Pierantoni Hospital, Forlì, Italy); Scarpa Aldo (University of Verona, Verona, Italy); Schneider Paul (Hirslanden Hospital Zurich, Switzerland); Tomezzoli Anna (Verona University Hospital, Verona, Italy); Vieth Michael (Klinikum 
Bayreuth, Bayreuth, Germany); Wotherspoon Andrew (The Royal Marsden NHS Foundation Trust, London and Surrey, United Kingdom); Zamboni Giuseppe (Sacro Cuore-Don Calabria Hospital, Negrar, Italy).

Funding None.

\section{Compliance with ethical standards}

Conflict of interest The authors declare that they have no conflict of interest.

Ethical standards This article does not contain any studies with human or animal subjects performed by any of the authors. There was no need to get informed consent.

\section{References}

1. Ferlay J, Soerjomataram I, Dikshit R, Eser S, Mathers C, Rebelo $\mathrm{M}$, et al. Cancer incidence and mortality worldwide: sources, methods and major patterns in GLOBOCAN 2012. Int J Cancer. 2015;136:E359-86.

2. Marrelli D, Pedrazzani C, Morgagni D, de Manzoni G, Pacelli F, Coniglio A, et al. Changing clinical and pathological features of gastric cancer over time. Bri J Surg. 2011;98:1273-83.

3. Wu H, Rusiecki JA, Zhu K, Potter J, Devesa SS. Stomach carcinoma incidence patterns in the United States by histologic type and anatomic site. Cancer Epidemiol Biomarkers Prev. 2009;18:1945-52.

4. Henson DE, Dittus C, Younes M, Nguyen H, Albores-Saavedra J. Differential trends in the intestinal and diffuse types of gastric carcinoma in the United States, 1973-2000: increase in the signet ring cell type. Arch Pathol Lab Med. 2004;128:765-70.

5. Laurén PA, Nevalainen TJ. Epidemiology of intestinal and diffuse types of gastric carcinoma. A time-trend study in Finland with comparison between studies from high- and low-risk areas. Cancer. 1993;71:2926-33.

6. Lauwers GY, Carneiro F, Graham DY, Curado M-P, Franceschi S, Montgomery E, Tatematsu M, Hattori T: Gastric Carcinoma. In: Bosman FT, Carneiro F, Hruban RH, Theise ND, editors. WHO classification of tumours of the digestive system, 4th ed. IARC Press: Lyon; 2010, pp. 48-58.

7. Piessen G, Messenger M, Leteurtre E, Jean-Pierre T, Mariette C. Signet ring cell histology is an independent predictor of poor prognosis in gastric adenocarcinoma regardless of tumoral clinical presentation. Ann Surg. 2009;250:878-87.

8. Taghavi S, Jayarajan SN, Davey A, Willis AI. Prognostic significance of signet ring gastric cancer. J Clin Oncol. 2012;30:3493-8.

9. Bamboat ZM, Tang LH, Vinuela E, Kuk D, Gonen M, Shah MA, et al. Stage-stratified prognosis of signet ring cell histology in patients undergoing curative resection for gastric adenocarcinoma. Ann Surg Oncol. 2014;21:1678-85.

10. Chon HJ, Hyung WJ, Kim C, Park S, Kim JH, Park CH, et al. Different prognostic implications of gastric signet ring cell carcinoma: Stage adjusted analysis from a single high-volume center in Asia. Ann Surg. 2017;265(5):946-53.

11. Piessen G, Messager M, Robb WB, Bonnetain F, Mariette C. Gastric signet ring cell carcinoma: how to investigate its impact on survival. J Clin Oncol. 2013;31:2059-60.

12. Baiocchi GL, D'Ugo D, Coit D, Hardwick R, Kassab P, Nashimoto A, et al. Follow-up after gastrectomy for cancer: the Charter Scaligero Consensus Conference. Gastric Cancer. 2016;19:15-20.
13. De Manzoni G, Baiocchi GL, Framarini M, De Giuli M, D’Ugo D, Marchet A, et al. The SIC-GIRCG 2013 consensus conference on gastric cancer. Updates Surg. 2014;66:1-6.

14. Zamboni G, Franzin G, Scarpa A, Bonetti F, Pea M, Mariuzzi $\mathrm{GM}$, et al. Carcinoma-like signet-ring cells in gastric mucosaassociated lymphoid tissue (MALT) lymphoma. Am J Surg Pathol. 1996;20:588-98.

15. Lee D, Ham IH, Son SY, Han SU, Kim YB, Hur H. Intratumor stromal proportion predicts aggressive phenotype of gastric signet ring cell carcinomas. Gastric Cancer. 2017;20:591-601.

16. Becker K, Mueller JD, Schumacher C, Ott K, Fink U, Busch $\mathrm{R}$, et al. Histomorphology and grading of regression in gastric carcinoma treated with neoadjuvant chemotherapy. Cancer. 2003;98:1521-30.

17. Mandard AM, Dalibard F, Mandard JC, Marnay J, Henry-Amar $\mathrm{M}$, Petiot JF, et al. Pathologic assessment of tumor regression after preoperative chemoradiotherapy of esophageal carcinoma. Clinicopathol Correlations Cancer. 1994;73:2680-6.

18. Philippron A, Bollschweiler E, Kunikata A, Plum P, Schmidt $\mathrm{C}$, Favi F, et al. Prognostic relevance of lymph node regression after neoadjuvant chemoradiation for esophageal cancer. Semin Thorac Cardiovasc Surg. 2016;28:549-58.

19. Hölscher AH, Drebber U, Schmidt H, Bollschweiler E. Prognostic classification of histopathologic response to neoadjuvant therapy in esophageal adenocarcinoma. Ann Surg. 2014;260:779-84.

20. Bollschweiler E, Hölscher AH, Metzger R, Besch S, Mönig SP, Baldus SE, et al. Prognostic significance of a new grading system of lymph node morphology after neoadjuvant radiochemotherapy for esophageal cancer. Ann Thorac Surg. 2011;92:2020-7.

21. Bollschweiler E, Besch S, Drebber U, Schröder W, Mönig SP, Vallböhmer D, et al. Influence of neoadjuvant chemoradiation on the number and size of analyzed lymph nodes in esophageal cancer. Ann Surg Oncol. 2010;17:3187-94.

22. Shapiro J, Biermann K, van Klaveren D, Offerhaus GJ, Ten Kate FJ, Meijer SL, et al. Prognostic value of pretreatment pathological tumor extent in patients treated with neoadjuvant chemoradiotherapy plus surgery for esophageal or junctional cancer. Ann Surg. 2017;265:356-62.

23. Nieman DR, Peyre CG, Watson TJ, Cao W, Lunt MD, Lada MJ, et al. Neoadjuvant treatment response in negative nodes is an important prognosticator after esophagectomy. Ann Thorac Surg. 2015;99:277-83.

24. Zanoni A, Verlato G, Giacopuzzi S, Motton M, Casella F, Weindelmayer J, et al. ypN0: Does it matter how you get there? Nodal downstaging in esophageal cancer. Ann Surg Oncol. 2016;23(Suppl 5):998-1004.

25. Mori M, Sakaguchi H, Akazawa K, Tsuneyoshi M, K Sueishi K, Sugimachi K. Correlation between metastatic site, histological type, and serum tumor markers of gastric carcinoma. Hum Pathol. 1995;26:504-8.

26. Min BH, Kim KM, Park CK, Lee JH, Rhee PL, Rhee JC, et al. Outcomes of endoscopic submucosal dissection for differentiatedtype early gastric cancer with histological heterogeneity. Gastric Cancer. 2015;18:618-26.

27. Miyamae M, Komatsu S, Ichikawa S, Kosuga T, Kubota T, Okamoto $\mathrm{K}$, et al. Histological mixed-type as an independent risk factor for nodal metastasis in submucosal gastric cancer. Tumour Biol. 2016;37:709-14.

28. Carneiro, F. Classification of gastric carcinoma. Curr Diag Pathol. 2017;4:5.

29. Stelzner S, Emmrich P. The mixed type in Laurén's classification of gastric carcinoma. Histologic description and biologic behavior. Gen Diagn Pathol. 1997;143:39-48.

30. Zheng HC, Li XH, Hara T, Masuda S, Yang XH, Guan YF, et al. Mixed-type gastric carcinomas exhibit more aggressive features 
and indicate the histogenesis of carcinomas. Virchows Arch. 2008;452:525-34.

31. Hanaoka N, Tanabe S, Mikami T, Okayasu I, Saigenji K. Mixedhistologic-type submucosal invasive gastric cancer as a risk factor for lymph node metastasis: feasibility of endoscopic submucosal dissection. Endoscopy. 2009;41:427-32.

32. Shimizu H, Ichikawa D, Komatsu S, Okamoto K, Shiozaki A, Fujiwara $\mathrm{H}$, et al. The decision criterion of histological mixed type in "T1/T2" gastric carcinoma-comparison between TNM classification and Japanese Classification of Gastric Cancer. J Surg Oncol. 2012;105:800-4.

33. Park HK, Lee KY, Yoo MW, Hwang TS, Han HS. Mixed carcinoma as an independent prognostic factor in submucosal invasive gastric carcinoma. J Korean Med Sci. 2016;31:866-72.

34. van der Post RS, Gullo I, Oliveira C, Tang LH, Grabsch HI, O'Donovan M, et al. Histopathological, molecular, and genetic profile of hereditary diffuse gastric cancer. Current knowledge and challenges for the future. Adv Exp Med Biol. 2016;908:371-91.

35. Kwon CH, Kim YK, Lee S, Kim A, Park HJ, Choi Y, et al. Gastric poorly cohesive carcinoma: a correlative study of mutational signatures and prognostic significance based on histopathological subtypes. Histopathology. 2018;72:556-68.

36. Japanese Gastric Cancer Association. Japanese classification of gastric carcinoma: 3rd English edition. Gastric Cancer. 2011;14:101-12.

37. Fujimoto A, Ishikawa $\mathrm{Y}$, Ishii $\mathrm{T}$, Yamada A, Igarashi $\mathrm{Y}$, Ohmoto Y, et al. Differences between gastric signet-ring cell carcinoma and poorly differentiated adenocarcinoma: a comparison of histopathologic features determined by mucin core protein and trefoil factor family peptide immunohistochemistry. Pathol Int. 2017;67:398-403. 